\title{
Polymorphism in the NLRP3 inflammasome-associated EIF 2AK2 gene and inflammatory bowel disease
}

\author{
GEENA PARAMEL VARGHESE ${ }^{1}$, LUDMILA UPOROVA ${ }^{1}$, JONAS HALFVARSON ${ }^{2}$, \\ ALLAN SIRSJÖ $^{1}$ and KARIN FRANSÉN ${ }^{1}$ \\ ${ }^{1}$ Department of Clinical Medicine, School of Health and Medical Sciences; ${ }^{2}$ Department of Gastroenterology, \\ Faculty of Medicine and Health, Örebro University, Örebro SE-70182, Sweden
}

Received February 26, 2014; Accepted November 19, 2014

DOI: $10.3892 / \mathrm{mmr} .2015 .3236$

\begin{abstract}
Inflammatory bowel disease (IBD) is the common name for numerous relapsing inflammatory conditions, and is the collective name for Crohn's disease (CD) and ulcerative colitis (UC). The activation of the inflammasome in the pathogenesis of IBD has recently been identified, however the underlying mechanisms remain unclear. An activator of the inflammasome is double-stranded RNA-dependent protein kinase $\mathrm{R}$, also termed EIF2AK2. A genetic alteration in the EIF $2 A K 2$ gene has previously been shown to be associated with Alzheimer's disease. The present study genotyped samples from a Swedish cohort of patients with IBD and healthy controls for an EIF $2 A K 2$ polymorphism. The rs2254958 polymorphism in the 5'-untranslated region of the EIF2AK2 gene was genotyped by TaqMan ${ }^{\circledR}$ single nucleotide polymorphism genotyping, followed by allelic discrimination. However, no significant association was determined between the rs2254958 polymorphism and the development of IBD, or clinical outcome. In conclusion, the results of the present study suggest that the rs2254958 polymorphism has a limited effect on the onset or progression of IBD.
\end{abstract}

\section{Introduction}

Inflammatory bowel disease (IBD) is the name for a group of gastrointestinal disorders, of which Crohn's disease (CD) and ulcerative colitis (UC) are the two most common subtypes. IBD is generally hypothesized to be a multifactorial condition caused by a combination of genetic, microbial and environmental factors (1). Among the genetic risk factors involved in IBD, genetic alterations in genes associated with intestinal homeostasis, microbial defense, innate immune system regu-

Correspondence to: Dr Karin Fransén, Department of Clinical Medicine, School of Health and Medical Sciences, Örebro University, SE-701 82 Örebro, Sweden

E-mail: karin.h.franzen@oru.se

Key words: protein kinase R, EIF2AK2, NLRP3, rs2254958, inflammasome, polymorphism lation, reactive oxygen species production, autophagy and regulation of adaptive immunity have been identified (2).

The NLRP3 inflammasome has previously been implicated in the pathogenesis of numerous inflammatory diseases, including IBD (3). The intracellular NLRP3 inflammasome consists of the sensor proteins NLRP3, ASC and pro-caspase-1; however, the mechanism for the assembly of the NLRP3 inflammasome remains poorly understood. Various stimuli, such as bacterial muramyl dipeptide, peptidoglycan, bacterial and viral RNA, bacterial toxins, low intracellular $\mathrm{K}^{+}$concentrations, ATP and urate crystals are known to induce the formation of the NLRP3 inflammasome (4-10). Upon activation of the NLRP3 inflammasome, caspase-1 is activated, followed by interleukin (IL)-1 $\beta$, IL-18 and the endogenous danger signal high-mobility group protein B1 (HMGB1) (11-14). Once activated HMGB1 is translocated from the nucleus to the cytoplasm, which facilitates its extracellular secretion (14). Elevated levels of HMGB1 have previously been detected in the stools of patients with IBD (15), thus suggesting a potential role for HMGB1 in the pathogenesis of IBD. Lu et al (16) previously demonstrated that one of the molecules responsible for inflammasome activation and HMGB1 release is the double-stranded RNA-dependent protein kinase R (PKR, also known as EIF2AK2) (16). PKR is an intracellular protein encoded by the EIF $2 A K 2$ gene on chromosome 2p22-p21, and has two RNA binding domains and a kinase domain (17). Previous studies have indicated that PKR is involved in various cell regulatory pathways, including antiviral activity, growth suppression, cell cycle regulation, transcriptional regulation and apoptosis (18). Lu et al (16) demonstrated that genetic deletion of $E I F 2 A K 2$ reduced activation of the NLRP3 inflammasome, whereas overexpression of EIF2AK2 increased the activity of the NLRP3 inflammasome. Numerous single nucleotide polymorphisms (SNPs) have been shown to be located in the EIF2AK2 gene. One of these, the rs2254958 SNP is located in the 5'-untranslated region (UTR) and has been associated with Alzheimer's disease, which has previously been identified as an inflammatory disease associated with NLRP3 activation $(19,20)$. The rs2254958 (C/T) polymorphism is located in the evolutionarily conserved SRp55 binding enhancer element of the EIF2AK2 gene, where interaction with the transcription factor is disrupted by the minor T-allele, but not the major C-allele (19). Bullido et al (19) also suggested, via virtual analysis of the 5'-UTR, 
Table I. Clinical characteristics of patients with inflammatory bowel disease.

\begin{tabular}{|c|c|c|}
\hline Characteristic & $\mathrm{UC}$ & $\mathrm{CD}$ \\
\hline \multicolumn{3}{|l|}{ Number of subjects (\%) } \\
\hline Female & $186(43)$ & $178(56)$ \\
\hline Male & $242(57)$ & $141(44)$ \\
\hline Age at diagnosis, years (mean $\pm \mathrm{SD}$ ) & $34.5 \pm 14.9$ & $30.6 \pm 13.7$ \\
\hline First-degree relative with IBD (\%) & $48(11)$ & $40(13)$ \\
\hline \multicolumn{3}{|l|}{ Smoking habits (\%) } \\
\hline Smoker & $55(13)$ & $103(34)$ \\
\hline Former smoker & $148(36)$ & $52(17)$ \\
\hline Never smoked & $215(51)$ & $152(49)$ \\
\hline \multicolumn{3}{|l|}{ Location at diagnosis (\%) } \\
\hline L1 ileal/+upper GI & & $89(28) /+4(1)$ \\
\hline L2 colonic/+upper GI & & $110(35) /+3(1)$ \\
\hline L3 ileocolonic/+upper GI & & $101(32) /+6(2)$ \\
\hline L4 upper GI & & $2(1)$ \\
\hline \multicolumn{3}{|l|}{ Behavior at diagnosis $(\%)$} \\
\hline B1 non-stricturing, non-penetrating & & $188(60)$ \\
\hline B2 stricturing & & $91(29)$ \\
\hline B3 penetrating & & $35(11)$ \\
\hline \multicolumn{3}{|l|}{ Extent at diagnosis $(\%)$} \\
\hline E1 proctitis & $109(26)$ & \\
\hline E2 left sided colitis & $139(33)$ & \\
\hline E3 extensive colitis & $170(41)$ & \\
\hline
\end{tabular}

UC, ulcerative colitis; CD, Crohn's disease; GI, gastrointestinal; IBD, inflammatory bowel disease; SD, standard deviation.

that the rs2254958 SNP may alter the activity of an exonic splicing enhancer. However, the role of this polymorphism in the development of IBD is currently unknown. The present study aimed to investigate the rs 2254958 polymorphism in the EIF2AK2 gene in a Swedish cohort of patients with IBD. The frequency of the SNP was then compared with the frequency in healthy controls from the same region and examined in association with disease phenotype data.

\section{Materials and methods}

Ethics. Ethical approval was obtained from the ethics committee of the Medical Faculty, Uppsala University (Uppsala, Sweden). Informed consent was obtained from all of the patients with IBD, as well as the healthy blood donors. The ethical considerations for the present study followed the principles of the Declaration of Helsinki.

Study subjects. A total of 747 Swedish patients with IBD (CD, $n=319$; UC, $n=428$ ) were recruited at Örebro University Hospital (Örebro, Sweden) between 2007 and 2009. Due to poor genotyping signal, only 730 samples were further analyzed. Diagnosis of IBD was based on standard clinical, endoscopic, radiologic and histologic criteria (21). Medical notes were scrutinized in order to classify disease characteristics, according to the Montreal classification (22). Blood samples were obtained in EDTA tubes and frozen at $-20^{\circ} \mathrm{C}$ until DNA extraction. Data on the clinical characteristics of the patients are presented in Table I. Healthy blood donors, without any history of gastrointestinal disease $(n=1,037)$, were recruited from Örebro University Hospital as controls. The mean age of the controls was 45 years old and the percentages of females and males were 42 and $58 \%$, respectively.

Genotyping of EIF2AK2 rs2254958 polymorphism. The EIF2AK2 rs2254958 polymorphism was genotyped in a similar manner to that previously described by Fransén et al (23). DNA was extracted from whole blood samples using QIAamp DNA Blood Maxi kit (Qiagen, Hilden, Germany), according to the manufacturer's instructions. The TaqMan ${ }^{\circledR}$ SNP Genotyping assay (C__11162026_20; Applied Biosystems/Life Technologies, Foster City, CA, USA) was used to genotype the samples for the rs2254958 polymorphism in the EIF2AK2 gene. The amplification mixtures contained 20 ng DNA, 1X TaqMan ${ }^{\circledR}$ Genotype PCR Master mix (Applied Biosystems/Life Technologies), 1X TaqMan ${ }^{\circledR}$ SNP Genotyping assay (Applied Biosystems/Life Technologies), including allele-specific probes and primers labeled with the two-allele specific fluorescent reporter dyes VIC ${ }^{\circledR}$ ( T allele) and FAM $^{\mathrm{TM}}$ (C allele), and Milli-Q water in a $10 \mu \mathrm{l}$ reaction. The PCR reactions were performed on the 7900HT Fast Real-Time PCR system (Applied Biosystems/Life Technologies), using 
Table II. Genotype frequencies of the rs2254958 polymorphism in the EIF2AK2 gene in patients with inflammatory bowel disease, as compared with healthy controls.

\begin{tabular}{|c|c|c|c|c|c|c|}
\hline & Genotype & Patients (\%) & Controls (\%) & OR & CI & $\mathrm{P}^{\mathrm{a}}$ \\
\hline \multirow[t]{3}{*}{ IBD } & TT & 127 (17) & 200 (19) & 1 & & \\
\hline & $\mathrm{CT}$ & $365(50)$ & $517(50)$ & 1.1 & $0.9-1.4$ & 0.42 \\
\hline & $\mathrm{CC}$ & 238 (33) & $320(31)$ & 1.2 & $0.9-1.5$ & 0.27 \\
\hline \multirow[t]{3}{*}{$\mathrm{CD}$} & $\mathrm{TT}$ & $58(19)$ & 200 (19) & 1 & & \\
\hline & $\mathrm{CT}$ & 153 (49) & $517(50)$ & 1.0 & $0.7-1.4$ & 0.91 \\
\hline & $\mathrm{CC}$ & $99(32)$ & $320(31)$ & 1.1 & $0.7-1.5$ & 0.73 \\
\hline \multirow[t]{3}{*}{$\mathrm{UC}$} & $\mathrm{TT}$ & $69(16)$ & 200 (19) & 1 & & \\
\hline & $\mathrm{CT}$ & $212(51)$ & $517(50)$ & 1.2 & $0.9-1.6$ & 0.29 \\
\hline & $\mathrm{CC}$ & 139 (33) & $320(31)$ & 1.3 & $0.9-1.8$ & 0.18 \\
\hline
\end{tabular}

${ }^{a}$ Uncorrected P-value. $\chi^{2}$ test was used to determine P-values. Odds ratio and confidence interval estimated using $2 \times 2$ contingency tables. CD, Crohn's disease; UC, ulcerative colitis; C, major allele; T, minor allele; OR, odds ratio; CI, 95\% confidence interval.

Table III. Allele frequencies of the rs 2254958 polymorphism in the EIF2AK2 gene in patients with inflammatory bowel disease, as compared with healthy controls.

\begin{tabular}{|c|c|c|c|c|c|c|}
\hline & Allele & Patients (\%) & Controls (\%) & OR & $\mathrm{CI}$ & $\mathrm{P}^{\mathrm{a}}$ \\
\hline \multirow[t]{2}{*}{ IBD } & $\mathrm{T}$ & $619(42)$ & 917 (44) & 1 & & \\
\hline & $\mathrm{C}$ & $841(58)$ & $1157(56)$ & 1.1 & $0.9-1.2$ & 0.28 \\
\hline \multirow[t]{2}{*}{$\mathrm{CD}$} & $\mathrm{T}$ & $269(43)$ & 917 (44) & 1 & & \\
\hline & $\mathrm{C}$ & $351(57)$ & $1157(56)$ & 1.0 & $0.9-1.2$ & 0.72 \\
\hline \multirow[t]{2}{*}{$\mathrm{UC}$} & $\mathrm{T}$ & $350(42)$ & 917 (44) & 1 & & \\
\hline & $\mathrm{C}$ & $490(58)$ & $1157(56)$ & 1.1 & $0.9-1.3$ & 0.21 \\
\hline
\end{tabular}

$\chi^{2}$ test used to determine P-values. Odds ratio and confidence interval estimated using $2 \times 2$ contingency tables. CD, Crohn's disease; UC, ulcerative colitis; C, major allele; T, minor allele; OR, odds ratio; CI, 95\% confidence interval. ${ }^{a}$ Uncorrected P-value.

96-well plates. The PCR conditions were set as follows: $10 \mathrm{~min}$ at $95^{\circ} \mathrm{C}, 40$ cycles of $15 \mathrm{sec}$ at $95^{\circ} \mathrm{C}$, followed by $60 \mathrm{sec}$ at $60^{\circ} \mathrm{C}$. The amplification was followed by post-read allelic discrimination analysis performed on the same apparatus used for PCR analysis.

Statistical analysis. The rs2254958 polymorphism was tested for Hardy-Weinberg equilibrium. Statistical analyses were performed using SPSS (SPSS Inc., Chicago, IL, USA) and Epi Info ${ }^{\mathrm{TM}}$ (Centers for Disease Control and Prevention, Atlanta, GA, USA) statistical packages. Associations between categorical variables were assessed by $\chi^{2}$ test or two-tailed Fisher's exact test where appropriate. The data are presented as uncorrected $\mathrm{P}$-values, odds ratio (OR) and $95 \%$ confidence interval $(\mathrm{CI}) . \mathrm{P} \leq 0.05$ was considered to indicate a statistically significant difference.

\section{Results}

Genotyping of the EIF2AK2 polymorphism rs2254958 in patients with IBD and healthy blood donors. The rs 2254958 polymorphism in the $E I F 2 A K 2$ gene was genotyped by TaqMan ${ }^{\circledR}$ genotyping of blood samples from 747 patients with IBD (319 with CD and 428 with UC) and 1,037 healthy controls. The polymorphism was found in Hardy-Weinberg equilibrium for the IBD and control groups. In the IBD group the genotype frequencies were as follows: $17 \%$ TT, $50 \% \mathrm{CT}$ and $33 \%$ CC (Table II). The corresponding percentages for the controls were $19 \%$ TT, $50 \%$ CT and $31 \%$ CC (Table II). The IBD group was then divided into patients with $\mathrm{CD}$ and patients with $\mathrm{UC}$; and similar genotype frequencies were evident in these groups, as compared with the whole IBD group (Table II). Furthermore, the allele frequency of the T allele in the whole IBD and control groups was 42 and 44\%, respectively (Table III). No significant differences were observed in the genotype or allele frequencies between the controls and the patients with IBD, either when comparing with the whole IBD group, or the separate CD and UC groups (Tables II and III).

The rs2254958 polymorphism was also compared with disease phenotype background data, however no significant association was evident in allele (Tables IV and V) or genotype frequencies (data not shown). 
Table IV. Allele frequencies of the rs 2254958 polymorphism in the EIF2AK2 gene for patients with Crohn's disease, as compared with healthy controls, with regards to sub phenotypes and clinical features.

\begin{tabular}{|c|c|c|c|c|c|}
\hline & \multicolumn{2}{|c|}{ Allele frequencies $(\%)$} & \multirow[b]{2}{*}{ OR } & \multirow[b]{2}{*}{ CI } & \multirow[b]{2}{*}{$\mathrm{P}$} \\
\hline & $\mathrm{T}$ & $\mathrm{C}$ & & & \\
\hline \multicolumn{6}{|l|}{ Male } \\
\hline Controls & $522(44)$ & $674(56)$ & 1 & & \\
\hline Patients & $118(42)$ & $162(58)$ & 0.9 & $0.7-1.2$ & 0.64 \\
\hline \multicolumn{6}{|l|}{ Female } \\
\hline Controls & $395(45)$ & $483(55)$ & 1 & & \\
\hline Patients & $151(44)$ & $189(56)$ & 0.9 & $0.7-1.2$ & 0.85 \\
\hline Controls total & $917(44)$ & $1157(56)$ & 1 & & \\
\hline \multicolumn{6}{|l|}{ Location at diagnosis ${ }^{\mathrm{a}}$} \\
\hline L1 ileal & $78(45)$ & $94(55)$ & 1.0 & $0.7-1.4$ & 0.77 \\
\hline L2 colonic & $92(43)$ & $120(57)$ & 0.9 & $0.7-1.2$ & 0.81 \\
\hline L3 ileocolonic & $80(40)$ & $118(60)$ & 0.8 & $0.6-1.1$ & 0.30 \\
\hline L4 upper GI & $3(75)$ & $1(25)$ & - & $0.32^{\mathrm{b}}$ & \\
\hline \multicolumn{6}{|l|}{ Behavior at diagnosis ${ }^{\mathrm{a}}$} \\
\hline $\begin{array}{l}\text { B1 non-stricturing, } \\
\text { non-penetrating }\end{array}$ & $149(41)$ & $211(59)$ & 0.8 & $0.7-1.1$ & 0.31 \\
\hline B2 stricturing & $84(47)$ & $96(53)$ & 1.1 & $0.8-1.4$ & 0.52 \\
\hline B3 penetrating & $31(44)$ & $39(56)$ & 1.0 & $0.6-1.6$ & 0.99 \\
\hline
\end{tabular}

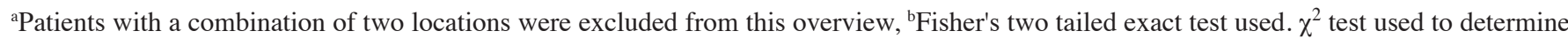
$\mathrm{P}$-values, unless otherwise stated. Odds ratio and confidence interval estimated using $2 \times 2$ contingency tables. T, minor allele; C, major allele; OR, odds ratio; CI, $95 \%$ confidence interval; GI, gastrointestinal.

Table V. Allele frequencies of the rs 2254958 polymorphism in the EIF2AK2 gene for patients with ulcerative colitis, as compared with healthy controls, with regards to sub phenotypes and clinical features.

\begin{tabular}{|c|c|c|c|c|c|}
\hline & \multicolumn{2}{|c|}{ Allele frequencies (\%) } & \multirow[b]{2}{*}{ OR } & \multirow[b]{2}{*}{ CI } & \multirow[b]{2}{*}{$\mathrm{P}$} \\
\hline & $\mathrm{T}$ & $\mathrm{C}$ & & & \\
\hline \multicolumn{6}{|l|}{ Male } \\
\hline Controls & $522(44)$ & $674(56)$ & 1 & & \\
\hline Patients & $194(41)$ & $284(59)$ & 0.8 & $0.7-1.0$ & 0.25 \\
\hline \multicolumn{6}{|l|}{ Female } \\
\hline Controls & $395(45)$ & $483(55)$ & 1 & & \\
\hline Patients & $156(43)$ & $206(57)$ & 0.9 & $0.7-1.1$ & 0.54 \\
\hline Controls total & $917(44)$ & $1157(56)$ & 1 & & \\
\hline \multicolumn{6}{|l|}{ Extent at diagnosis } \\
\hline E1 proctitis & $94(44)$ & $118(56)$ & 1.0 & $0.7-1.3$ & 0.97 \\
\hline E2 left sided colitis & $111(41)$ & $159(59)$ & 0.8 & $0.6-1.1$ & 0.33 \\
\hline E3 extensive colitis & $137(41)$ & $201(59)$ & 0.8 & $0.6-1.0$ & 0.20 \\
\hline
\end{tabular}

$\chi^{2}$ test used to determine P-values, unless otherwise stated. Odds ratio and confidence interval estimated using $2 \times 2$ contingency tables. T, minor allele; C, major allele; OR, odds ratio; CI, 95\% confidence interval.

\section{Discussion}

The involvement of the inflammasome in the pathogenesis of IBD, including CD and UC, has been the focus of numerous previous studies (3,24-27). Overexpression of IL-1 $\beta$ and IL-18 in the mucosa of patients with IBD has previously been detected, supporting the role of inflammasome activation in IBD (28). However, conflicting evidence has been presented regarding 
the association between IBD and polymorphisms in the genes associated with the NLRP3 inflammasome (24-27,29,30). The present study genotyped DNA samples for a polymorphism in the inflammasome activating and HMGB1 regulating EIF2AK2 gene in IBD. The $\mathrm{C}$ allele and the $\mathrm{CC}$ genotype of this polymorphism have previously been associated with Alzheimer's disease (19). However, in the present study, no significant associations were detected in the genotype or allele frequencies of the polymorphism in patients with IBD, as compared with normal controls. Similarly, no associations were observed when the patients with UC and CD were analyzed separately. Furthermore, the present study compared the genotype and allele frequencies with phenotypic features, however no association was identified. The genotype and allele frequencies in the present study were similar to those described in the National Center for Biotechnology Information SNP database for the European population (http://www.ncbi.nlm.nih. gov/projects/SNP/snp_ref.cgi?rs=2254958). Bullido et al (19) previously determined an association between the EIF $2 A K 2$ polymorphism and Alzheimer's disease in a Spanish cohort. Conversely, these results were questioned by a recent study and the findings could not be replicated in a Canadian cohort (31).

The lack of an association between IBD and the rs 2254958 polymorphism in the EIF $2 A K 2$ gene in the present study was unexpected. Hypothetically, the lack of association presented in this study cannot exclude any possible association in another population. It may also depend on the functionality of the SNP, or an alternative mechanism for EIF2AK2/PKR activation in IBD. EIF2AK2/PKR was initially suggested to be a key antiviral protein, due to its dsRNA binding functions; however, recent studies have shown that bacterial components, intracellular stress and free fatty acids induce autophosphorylation of PKR (32-34). Therefore, the role of diverse pathogens in PKR sensing for the assembly of the inflammasome in IBD remains to be elucidated.

In conclusion, the present study investigated the role of the rs2254958 EIF2AK2 polymorphism in patients with IBD and healthy controls; however, no significant association was detected. These results suggest that the rs2254958 polymorphism has a limited role in the development of IBD. Further analysis in additional cohorts and functional analysis of the polymorphism in IBD are therefore required.

\section{Acknowledgements}

The present study was supported by Örebro University (Örebro, Sweden), Magnus Bergvalls foundation and by grants from BengtIhre's Foundation, Nanna Svartz's Foundation, Örebro University Hospital Research Foundation, Örebro County Research Foundation, the Swedish Foundation for Gastrointestinal Research and the Swedish Research Council (grant no. 521-2011-2764). The funders had no role in study design, data collection and analysis, decision to publish, or preparation of the manuscript.

\section{References}

1. Pedersen J, Coskun M, Soendergaard C, Salem M and Nielsen OH: Inflammatory pathways of importance for management of inflammatory bowel disease. World J Gastroenterol 20: 64-77, 2014.
2. Khor B, Gardet A and Xavier RJ: Genetics and pathogenesis of inflammatory bowel disease. Nature 474: 307-317, 2011.

3. Strowig T, Henao-Mejia J,Elinav E and Flavell R: Inflammasomes in health and disease. Nature 481: 278-286, 2012.

4. Martinon F, Agostini L, Meylan E and Tschopp J: Identification of bacterial muramyl dipeptide as activator of the NALP3/cryopyrin inflammasome. Curr Biol 14: 1929-1934, 2004.

5. Kanneganti TD, Body-Malapel M, Amer A, et al: Critical role for cryopyrin/Nalp3 in activation of caspase-1 in response to viral infection and double-stranded RNA. J Biol Chem 281: 36560-36568, 2006

6. Kanneganti TD, Özören N, Body-Malapel M, et al: Bacterial RNA and small antiviral compounds activate caspase-1 through cryopyrin/Nalp3. Nature 440: 233-236, 2006.

7. Schmitz J, Owyang A, Oldham E, et al: IL-33, an interleukin-1-like cytokine that signals via the IL-1 receptor-related protein ST2 and induces T Helper type 2-associated cytokines. Immunity 23: 479-490, 2005.

8. Petrilli V, Papin S, Dostert C, Mayor A, Martinon F and Tschopp J: Activation of the NALP3 inflammasome is triggered by low intracellular potassium concentration. Cell Death Differ 14: 1583-1589, 2007.

9. Mariathasan S, Weiss DS, Newton K, et al: Cryopyrin activates the inflammasome in response to toxins and ATP. Nature 440: 228-232, 2006.

10. Martinon F, Petrilli V, Mayor A, Tardivel A and Tschopp J: Gout-associated uric acid crystals activate the NALP3 inflammasome. Nature 440: 237-241, 2006.

11. Bryant $C$ and Fitzgerald KA: Molecular mechanisms involved inflammasome activation. Trends Cell Biol 19: 455-464, 2009.

12. Agostini L, Martinon F, Burns K, McDermott MF, Hawkins PN and Tschopp J: NALP3 forms an IL-1 $\beta$-processing inflammasome with increased activity in Muckle-Wells Autoinflammatory disorder. Immunity 20: 319-325, 2004

13. Bauernfeind F, Ablasser A, Bartok E, et al: Inflammasomes: current understanding and open questions. Cell Mol Life Sci 68: 765-783, 2011.

14. Lamkanfi M, Sarkar A, Vande Walle L, et al: Inflammasome-dependent release of the alarmin HMGB1 in endotoxemia. J Immunol 185: 4385-4392, 2010.

15. Vitali R, Stronati L, Negroni A, et al: Fecal HMGB1 is a novel marker of intestinal mucosal inflammation in pediatric inflammatory bowel disease. Am J Gastroenterol 106: 2029-2040, 2011.

16. Lu B, Nakamura T, Inouye K, et al: Novel role of PKR in inflammasome activation and HMGB1 release. Nature 488: 670-674, 2012

17. Dey M, Cao C, Dar AC, et al: Mechanistic link between PKR dimerization, autophosphorylation, and eIF2alpha substrate recognition. Cell 122: 901-913, 2005.

18. Williams BR: Role of the double-stranded RNA-activated protein kinase (PKR) in cell regulation. Biochem Soc Trans 25: 509-513, 1997.

19. Bullido MJ, Martinez Garcia A, Tenorio R, et al: Double stranded RNA activated EIF2 alpha kinase (EIF2AK2;PKR) is associated with Alzheimer's disease. Nerobiol Aging 29: 1160-1166, 2008.

20. Heneka MT, Kummer MP, Stutz A, et al: NLRP3 is activated in Alzheimer's disease and contributes to pathology in APP/PS1 mice. Nature 493: 674-678, 2013.

21. Lennard-Jones JE: Classification of inflammatory bowel disease. Scand J Gastroenterol 24: 2-6, 1989.

22. Silverberg MS, Satsangi J, Ahmad T, et al: Toward an integrated clinical, molecular and serological classification of inflammatory bowel disease: report of a working party of the 2005 montreal world congress of gastroenterology. Can J Gastroenterol 19: 5-36, 2005.

23. Fransén K, Franzén P, Magnuson A, et al: Polymorphism in the retinoic acid metabolizing enzyme CYP26B1 and the development of Crohn's disease. PLoS One 8: e72739, 2013.

24. Franke A, Rosenstiel P,Balschun T, et al: No association between the TUCAN (CARD8) Cys10Stop mutation and inflammatory bowel disease in a large retrospective German and clinically well-characterized Norwegian sample. Gastroenterology 132: 2080-2081, 2007.

25. Büning C, Schmidt HH, Molnár T, et al: No association of the CARD8 (TUCAN) c.30T $>$ A (p.C10X) variant with Crohns disease: A study in 3 independent European Cohorts. Inflamm Bowel Dis 14: 332-337, 2008

26. Fisher SA, Mirza MM, Onnie CM, et al: Combined evidence from three large British association studies rejects TUCAN/CARD8 as an IBD susceptibility gene. Gastroenterology 132: 2078-2080, 2007.

27. McGovern DPB, Butler H, Ahmad T, et al: TUCAN (CARD8) genetic variants and inflammatory bowel disease. Gastroenterology 131: 1190-1196, 2006. 
28. Zaki MH, Lamkanfi $M$ and Kanneganti TD: The Nlrp3 inflammasome contributions to intestinal homeostasis. Trends Immunol 32: 171-179, 2011.

29. Schoultz I, Verma D, Halfvarsson J, et al: Combined polymorphisms in genes encoding the inflammasome components NALP3 and CARD8 confer susceptibility to crohn's disease in swedish men. Am J Gastroenterol 104: 1180-1188, 2009.

30. Verma D, Lerm M, Blomgran Julinder R, Eriksson P, Söderkvist P and Särndahl E: Gene polymorphisms in the NALP3 inflammasome are associated with interleukin-1 production and severe inflammation: relation to common inflammatory diseases? Arthritis Rheum 58: 888-894, 2008.
31. Palomer E, ILL-Raga G, Tajes M, et al: PKR and PP1C polymorphisms in Alzheimer's disease risk. Neurosci Med 2: 226-231, 2011.

32. Hsu LC, Park JM, Zhang K, et al: The protein kinase PKR is required for macrophage apoptosis after activation of Toll-like receptor 4. Nature 428: 341-345, 2004

33. Nakamura T, Furuhashi M, Li P, et al: Double-stranded RNA-dependent protein kinase links pathogen sensing with stress and metabolic homeostasis. Cell 140: 338-348, 2010.

34. Lu B, Wang H, Andersson U and Tracey KJ: Regulation of HMGB1 release by inflammasomes. Protein Cell 4: 163-167, 2013. 